DOI: https://doi.org/10.24867/05GI11Obradovic

\title{
INFORMACIONE TEHNOLOGIJE U UPRAVLJANJU INTEGRISANIM LANCIMA SNABDEVANJA
}

\section{INFORMATION TECHNOLOGIES IN MANAGING INTEGRATED SUPPLY CHAINS}

\author{
Marko Obradović, Fakultet tehničkih nauka, Novi Sad
}

\section{Oblast - Inženjerski menadžment}

Kratak sadržaj - U radu je na originalan nacin prikazano upravljanje lancima snabdevanja sa akcentom na savremene trendove $i$ alate koji se u upravljanju koriste. Definisano je mesto upravljanja lancima snabdevanja u logistici i generalno u poslovanju..

Ključne reči: Integracija, ERP, SAP, Blockchain

\begin{abstract}
This paper in original way presents the management of supply chains with the emphasis on modern trends and tools that are used in original way. The place of supply chain management in logistics and generally in business is defined.
\end{abstract}

Key words: Integration, ERP, SAP, Blockchain

\section{UVOD}

Lanac snabdevanja za svrhu ima zadovoljenje potreba i zahteva krajnjeg korisnika i pružanje usluge ili proizvoda više povezanih dobavljača. Upravljanje lancem snabdevanja (eng. Supply Chain Management) može se definisati kao mreža međusobno povezanih poslovnih procesa koji treba da budu izgrađeni unutar organizacije $i$ njenog relevantnog okruženja. SCM je integracija informacionih tehnologija, nauke o menadžmentu i menadžerske prakse, u cilju optimizacije tokova informacija, materijalnih, ljudskih, novčanih resursa i proizvoda kroz poslovne procese i interakciju poslovnih partnera radi efektivne i efikasne podrške sistema lanca snabdevanja i logističkih procesa. Danas, u vreme široke zastupljenosti informacionih tehnologija, softverska rešenja nalaze izuzetnu primenu u pravcu optimizacije donošenja odluka u vezi sa lancem snabdevanja. Njihova integracija predstavlja obimnu poslovnu strategiju koja povezuje što je moguće više karika u lancu, kroz što bliže međusobne poslovne odnose sa ciljem skraćivanja vremena za reakciju i proizvodnju, smanjivanje troškova i otpada tako da svaka karika u lancu profitira.

\section{ENTERPRISE RESOURCE PLANING - ERP SISTEMI}

Digitalna transformacija se prvo razvija unutar same organizacije, potom između njenih partnera, a na kraju u globalnom outsourcingu između organizacija i partnera kroz ceo lanac poslovnih mreža.

\section{NAPOMENA:}

Ovaj rad proistekao je iz master rada čiji mentor je bio dr Stevan Milisavljević, vanr. prof.
Sistemi obrade transakcija se $u$ današnje vreme izrađuju modularno i integralno, dok im strukturu čine informacioni moduli ili informacioni podsistemi. APICS objašnjava ERP na sledeći način: ERP predviđa i balansira ponudu i potražnju, tako da se može reći da je to skup alata za predviđanje, planiranje i raspoređivanje resursa na nivou kompanije koji povezuje kupce i dobavljače $u$ jedan lanac snabdevanja, primenjuje dokazane najbolje prakse u donošenju odluka, koordinira prodaju, marketing, operacije, logistiku, nabavku, finansije, razvoj proizvoda i upravljanje ljudskim resursima.

Koraci pri uvođenju tipičnog sistema su:

- Korak 1: Priprema projekta (Prepare stage)

- Korak 2: Snimanje procesa u organizaciji, dokumentovanje procesa (Plan stage)

- Korak 3: Konfigurisanje sistema (Analyze Stage)

- Korak 4: Testiranje i validacija sistema (Execute Stage)

- Korak 5: Konačne pripreme (Validate stage)

- Korak 6: Oživljavanje - početak rada (Deploy)

U empirijske prednosti spadaju:

Jedno multifunkcionalno rešenje sa jedinstvenom bazom podataka i zajedničkim interfejsom, za razliku od nefleksibilnih softverskih rešenja koja slabo komuniciraju i nemaju zajednički interfejs. Takođe, smanjuje se broj ljudi za dalji razvoj i održavanje. Kontrola kritičnih poslovnih procesa $u$ područjima poput nabavke, skladištenja, proizvodnje, distribucije, prodaje, ljudskih resursa, finansija, računovodstva i dr. Pružanje različitih servisa kupcima i podizanje imidža organizacije. Premošćavanje informacionog gepa ne samo unutar jedne organizacije, nego i na nivou više organizacija, bez obzira na njihovu lokaciju. Puna back office podrška informacionog sistema organizacije što rezultira i integracijom front office rešenja. Bez ERP-a ne bi bilo ni integracije SCM-a, CRM-a i drugih savremenih rešenja. Sprečavanje nedostatka sirovina i materijala za nesmetano odvijanje proizvodnje, podizanje produktivnosti, uravljanje zalihama i skladištem, pravoremenom isporukom, upravljanje kvalitetom, upravljanje gotovinom i obezbeđivanje servisa kupcima; Uvođenje najsavremenijih informacionih tehnologija u organizaciju: EDI, Video conferencing, e-Commerce i ostalih; Veći pristup zaposlenih ažurnim i sveobuhvatnim podacima, kako bi se obezbedilo efikasnije donošenje strateških i operativnih upravljačkih odluka; Unapređenje procesa kroz sredstva poslovne inteligencije (Decision Support Systems, Data Mining, Executive Information Systems i dr.); Jedinstvena i sigurna zaštita podataka [2]. 
Odabir ERP rešenja, odnosno njegovog dobavljača, odvija se na osnovu polaznih pretpostavki o korišćenju sistema i vezan je za definisane ciljeve i očekivanja njihovog ispunjenja, kao i rezultate cost-benefit analize.

U kriterijume spadaju: Podrška industrijskoj grani, potreban stepen prilagođavanja, veličina poslovnog sistema i nivo podrške postojećim ključnim procesima.

Na sledećim grafikonima prikazan je uporedni pregled tri softverska rešenja $u$ oblasti upravljanja poslovnim procesima (QAD, Microsoft Dynamics NAV, SAP). Broj kriterijuma koji je analiziran: Finansije 1.017, ljudski resursi 457, Proizvodni menadžment 1.081, upravljanje procesom proizvodnje 199, upravljanje inventarom 193, upravljanje nabavkom 273, upravljanje kvalitetom 82, upravljanje prodajom 237, tehnologija proizvoda 177 [5].

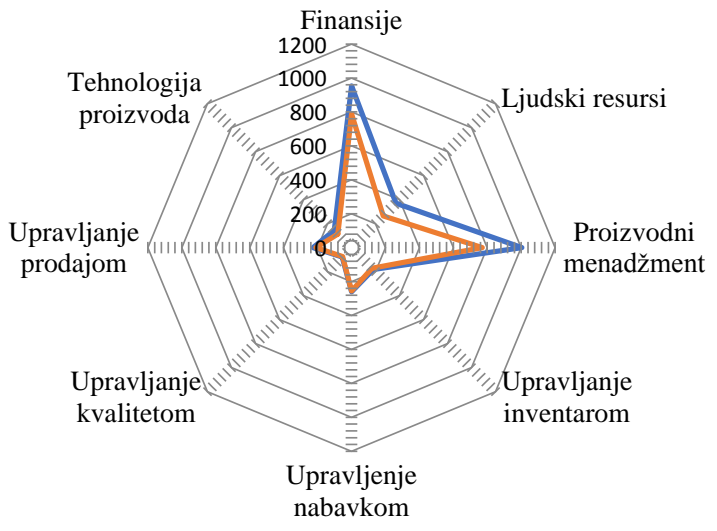

SAP S/4HANA D Dynamics 365

Grafikon 1. Uporedni pregled ERP sistem SAP S/4HANA i Microsoft Dynamics 365.

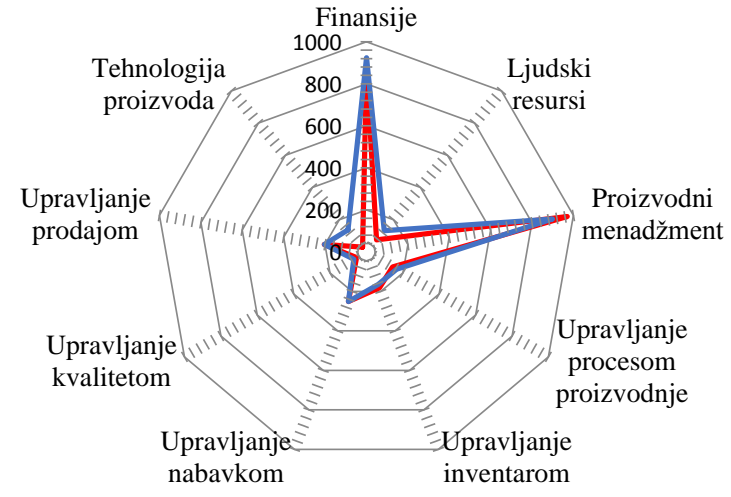

—QAD Enterprise Applications SAP S 4HANA

Grafikon 2. Uporedni pregled ERP sistema SAP HANA $i$ QAD Enterprise Applications.

Prema dostupnim finansijskim izveštajima, najuspešnija kompanija u proizvodnji poslovnih softvera (SAP) tokom 2018. godine je ostvarila sledeće rezultate: Prihod od pretplate korsinika na Cloud usluge i usluge podrške
5.205 milijardi EUR; prihod od Cloud-a i softvera 21.577 milijardi EUR; Operativni profit 7.480 milijardi; neto ocena korisnika 22 i indeks uključenosti zaposlenih $84 \%$. Što se ostalih pokazatelja tiče, u odnosu na 2017. godinu broj zaposlenih je porastao sa 88.543 na 96.498 ; zarade po akciji sa 3,35 na 3,42 ; dividenda po akciji sa 1,40 na 4,50 .

SAP rešenja uključuju nekoliko funkcionalnih modula koji podržavaju transakcije u izvršenju ključnih poslovnih procesa. Finansijsko računovodstvo i kontrola zajedno formiraju modul pod nazivom SAP FICO. Osim funkcija saržanih u nazivu, tu spada $\mathrm{i}$ investicioni menadžment $\mathrm{i}$ upravljanje blagajnom. Nakon njega, Upravljanje finansijskim aspektom lanca snabdevanja (FSCM), Upravljanje materijalima (MM), Prodaja i distribucija (SD), Izvršenje logističkih procesa (LE), Planiranje proizvodnje (PP), Upravljanje kvalitetom (QM), Održavanje fabrike (PM), Projektni sistemi (PS), Ljudski resursi (HR).

\section{DIGITALNI LANAC SNABDEVANJA}

Digitalizacija lanca snabdevanja počiva na inteligentnim preduzećima. Ona predstavljaju sisteme gde menadžment znanja i ostala rešenja poslovne inteligencije omogućavaju produbljene analize potrebne za pretvaranje sirovih podataka $\mathrm{u}$ korisne informacije. Umesto prognoziranja prodaje, teži se osetiti tražnju, realizovati ne samo jednu porudžbinu već razmišljati o korisničkom iskustvu (holistički prilaz).

Integrisani procesi poslovnog planiranja kroz celokupni lanac snabdevanja daju mogućnost korisniku da razdvoji fizički i digitalni svet i da osigura da su klijenti na centralnom mestu u svakoj fazi poslovanja. Fizička imovina se elektronski projektuje preko svog klona odnosno „digitalnog blizanca“, i omogućava donosiocu odluke da se racionalno opredeli za određeni scenario, pre samog delovanja i bez obzira da fazu životnog ciklusa proizvoda.

Poslovne mogućnosti portfolija digitalnih proizvoda $\mathrm{u}$ oblasti dizajna obuhvataju: Menadžment portfolija i projekata, menadžment kolaboracije i zahteva, razvoj i konfiguraciju, troškove životnog ciklusa i usklađenost proizvoda, prenos u proizvodnju.

U oblasti planiranja, SAP-ov paket ERP sistema uključuje: Kontrolni toranj lanca snabdevanja (povezuje različite izvore i omogućava preglednost na čitavoj mreži); Planiranje prodaje i operacija (razmatra finansijske implikacije svake akcije, kako bi se došlo do finansijski održivog, tehnički izvodljivog i strateški usklađenog plana); Analiza tražnje; Analiza zaliha (koristi multi-ešalonsku optimizaciju inventara - MEIO, a kao dodatak ovaj podmodul podržava i prva dva koraka MRPa poznata kao DDMRP); Analiza reakcije i ponude (koristi tri algoritma: neograničenu heuristiku, ograničenu optimizaciju sa ograničenjem troškova i kapaciteta i ograničenu prioritetnu potražnju sa pravičnom raspodelom).

Inteligentno proizvodno preduzeće koje implementira proizvodnju 4.0 prelazi sa masovne proizvodnje na masovnu individualizaciju, sa outsource proizvodnje na respoređenu proizvodnu mrežu. 
Deterministički modeli i papirne instrukcije zamenjeni su 3D instrukcijama i predviđajućim modelima. Kapitalno intenzivna proizvodnja gravitira ka uslužnoj, a manuelni procesi postaju visoko automatizovani.

$\mathrm{Na}$ osnovu istraživanja o digitalnom upravljanju kompanijskom imovinom dobijeni su sledeći rezultati: $76 \%$ organizacija smatra da je važno predvitdeti potencijalne neuspehe pomoću pouzdanih modela podataka; $21 \%$ organizacija uspešno sprovodi prediktivno i preventivno održavanje; $83 \%$ organizacija smatra da je važno da procesi upravljanja imovinom i povezani merni podaci budu standardizovani u svim objektima i da se redovno prate; $13 \%$ organizacija može upravljati imovinom na osnovu analize podataka sa senzora $u$ realnom vremenu i istorijskih podataka o održavanju [6].

\section{ULOGA LOGISTIKE U DIGITALNOM LANCU SNABDEVANJA}

Digitalna transpofmacija posebno je neophodna $u$ fazi logistike. Istraživanja o digitalnoj spremnosti pokazuju da kompanije jasno vide potrebu da digitalno transformišu svoje logističke procese. $34 \%$ ogranizacija je u mogućnosti da optimizuje i konsoliduje narudžbine i pošiljke u distributivnim centrima, trgovinama i direktnim potrošačkim kanalima; $65 \%$ smatra da je važno integrisati procese $i$ sisteme lanca snabdevanja sa ključnim prevoznicima, špediterima i trećim stranama (3rd party logistics); $70 \%$ maloprodavaca želi da ima uvid u zalihe na globalnom nivou [6].

$\mathrm{Na}$ logsitičku industriju utiču mnogobrojni globalni trendovi u koje spadaju: globalizacija, demografske promene i urbanizacija, digitalizacija i tehnološki razvoj, održivi razvoj, opterećenje saobraćajne i transportne infrastrukture, promene centara ekonomske aktivnosti, politička nestabilnost, nov način poslovanja, elektronska trgovina, struktura lanca snabdevanja, ponašanje potrošača itd. Krajem prošlog veka elektronska trgovina postaje prilično aktuelna. Sa njenim porastom rastu $i$ logistički problemi, tako da je ova oblast sve važnija provajderima logističkih usluga.

Među predvodnicima u oblasti e-trgovine i primeni novih tehnologija u oblasti logistike ističu se kineski giganti Alibaba i JingDong (JD). JD trenutno upravlja sa preko 20 logističkih parkova koji su među najaumotatizovanijim centrima u Aziji. Koriste mrežu od 550 skladišta ukupne površine $12.000 .000 \mathrm{~m}^{2}$. Razvojem logističke mreže upravlja laboratorija pod nazivom JD-X čiji je fokus na automatizovane mogućnosti opskrbljivanja, uključujući bespilotne letelice $\mathrm{i}$ autonomna vozila za isporuku. Obzirom da će do 2025. godine Kina postati najveće svetsko $5 \mathrm{G}$ tržište, sa oko 460 miliona priključaka $(28 \%$ od ukupnog broja na globalnom nivou), logističko prilagođavanje $5 \mathrm{G}$ tehnologiji od strane JD-a uveliko je u toku, naročito sa aspekta izračunavanja ruta vozila i bržoj analizi obimnih informacija. Njihova platforma na dnevnom nivou prikupi čak 31 petabajt podataka. Alibabin pristup organizaciji transporta je drugačiji. Koristi se kolaporativni pristup, a fokus nije samo na Kini već i na okolnim zemljama. Mreža za isporuku pokriva 224 zemalja i regiona na globalnom nivou i 2.800 okruga u Kini. Obrađuje podatke sa $70 \%$ svih kineskih pošiljki, u proseku 42 miliona dnevno. Sarađuje sa više od 90 domaćih i stranih partnera, zapošljava više od 2 miliona radnika i kordinira rad 230.000 vozila i 180.000 isporučnih stanica. Mreža prima više od 800 miliona dnevnih ažuriranja statusa isporuke na svojoj platformi.

Slićni modeli konsolidacije pošiljki primenjuju i ostale kompanije. Bilo da se radi o organizaciji isporuke ili povlačenju proizvoda sa tržišta praktikuje se metod hub and spoke, a jedan od inovativnih poslovnih modela zbirnog transporta je i Uber for Freight.

Što se organizovanja skladišta tiče, uzimanje/biranje materijala u skladištu jedan je od najvažnijih procesa $u$ logistici. Razlikuje se nekoliko različitih sistema koji se mogu izabrati u zavisnosti od specifičnih uslova: klasični sistem biranja (po listi), sistem sa radio frekvencijom, sa glasom, svetlom, sistem podrške.

Danas mnoge kompanije nude hardver i softver kojima se pomenute tehnologije lako mogu implementirati ili samo dopuniti postojeći ERP sistem i optimizovati proces odabira. Njihovi rezultati ogledaju se u povećanju tačnosti pošiljke od 99,99\% i većoj bezbednosti operatera.

Operacije rukovanja materijalom trebalo bi mehanizovati i/ili automatizovati gde god je moguće kako bi se unapredila efikasnost operacija, povećala pouzdanost, poboljšala doslednost i predvidljivost i smanjili operativni troškovi. Automatski vođena vozila (eng. Automated Guided Vehicles - AGV) u upotrebi su već nekih šesdesetak godina. Radi se o industrijskim vozilima bez vozača, obično pogonjenim baterijama i električnim motorima. Težine tereta koje mogu prevoziti su veoma velikog opsega, od lakih tereta od svega nekoliko kilograma, pa do tereta težine preko 100 tona. AGV koja za Alibabu proizvodi Quicktron mogu se kretati brzinom od 1,5 metara u sekundi i nositi i do 500 kilograma. Takođe, mogu se rotirati za 360 stepeni radi lakšeg pristupa policama i međusobno detektovati, kako bi izbegli sudar. Veoma su upotrebljivi i automatski se približe punjaču kada je baterija skoro prazna.

Za kretanje robe kroz lanac snabdevanja koristi se tehnologija identifikacije radio frekvencija (RFID). RFID koristi minijaturne tagove (etikete) sa ugrađenim mikročipovima koji sadrže podatke o nekom proizvodu. Tag čini memorija gde su ti podaci skladišteni i antena koja emituje radio talase. Kada RFID dođe $\mathrm{u}$ domet čitača, tag se registruje i emituje podatke o proizvodu. Čitač ih potom prihvata, dekodira $\mathrm{i}$ šalje kroz žičanu ili bežičnu mrežu do centralnog računara na dalju obradu. Razlikuju se aktivni i pasivni RFID tagovi. Aktivni imaju integrisanu sopstvenu bateriju koja služi kao izvor energije, većih su dimenzija, opseg očitavanja im je duži, a vek trajanja oko 10 godina. Za razliku od njih, pasivni nemaju izvor energije, već istu dobijaju od RFID čitača, manjih su dimenzija i ujedno lakši, sa manjim opsegom čitanja i neograničenim vekom trajanja.

\section{BLOCKCHAIN}

Radi se o arhitektonskom konceptu koji nudi otvorenu, distribuiranu glavnu knjigu transakcija, koja može efikasno i trajno evidentirati transakcije između stranaka.

Tehnologije na kojima se ovaj koncept zasniva su: Peerto-peer mreže, kriptografija i Hash algoritmi, Konsenzusni algoritmi i baze podataka. 
U sprečavanju krivotvorenja, ubrzavanju procesa i stvaranju jedinstvenog izvora istine, primeri primene Blockchain-a dolaze iz različitih sfera:

Tržište farmaceutskih proizvoda. Ovde je Blockchain pozicioniran kao sredstvo za rešavanje problema falsifikovanja lekova kroz lance snabdevanja u Severnoj Americi. Predloženo rešenje bilo je da nosioci autorizacije tržišta (oni koji su ovlašćeni da se bave trgovinom lekovima i farmaceutskim proizvodima) pišu Hash kodove serijskih brojeva kako na same proizvode, tako i u Blockchain. Posrednici mogu da skeniraju serijski proizvod koristeći mobilnu aplikaciju, koja proverava autentičnost proizvoda i potrvrđuje da li može legalno da uđe (ponovo) na tržište.

U sferi telekomunikacija, u saradnji SAP-a, Deutche Telekoma i Camelot IT Laba, stvorena je jedinstvena mreža za bezbednost bežičnih uređaja zasnovana na Blockchain-u kako bi se ukradenim telefonima onemogućio pristup mobilnoj mreži. Ovakvoj listi IMEI brojeva mogu pristupiti mrežni operateri, prodavci hardvera, javne vlasti i drugi, kako bi brzo i efikasno odstranili kompromitovani telefon sa svoje mobilne mreže. Postoji i druga strana. Zahvaljujući dodeljenim administratoskim funkcijama, oni mogu i da otključaju uređaj kada se originalni vlasnik potvrdi.

Upravo u borbi protiv krivotvorenih proizvoda, kompanije sarađuju sa organizacijom kakva je Vechain koja koristi Blockchain i pametne tagove (NFC/RFID/QR kod) za implementaciju sledivosti celokupnog upravljanja životnim ciklusom proizvoda. Tako se jasno može utvrditi da li je proizvod originalan. $U$ autoindustriji, preko svoje Blockchain platforme nazvane VechainThor, svakom vozilu dodeli se poseban identifikacioni broj (šifra) i digitalna knjiga (pasoš) koja pokriva celokupni životni vek vozila. Broj šasije odnosno motora bi se mogao uzeti kao primer. Tako bi se na jednom mestu dobili podaci ne samo o automobilu kao celini, već i o svim njegovim bilo originalnim bilo polovnim komponentama. Koristeći te autentične podatke koji se čuvaju na Blockchainu, moguće je poceniti kvalitet i autentičnost auto delova. Osim toga, vlasnik vozila može omogućiti pristup tim podacima provajderima usluga (trećim stranama) kao što su osiguravajuće kuće, prodavci polovnih automobila, finansijske institucije i slično.

\section{ZAKLJUČAK}

Današnji lanci snabdevanja izuzetno su kompleksni, tako da svako kretanje robe, usluga i informacija generiše veliki broj podataka, čijom se analizom mogu proizvesti neophodni pokazatelji za adekvatno anticipiranje i prevenciju potencijalnih problema. Zahvaljujući pojavi ERP sistema, stvorena je jedinstvena baza podataka i omogućena jednostavnija i brža komunikacija između funkcionalnih jedinica unutar firme. Međutim, pri izboru odgovarajućeg ERP sistema, svaka kompanija se mora voditi individualnim kriterijumima poput veličine sistema, karakteristikama date industrije i potrebnom stepenu prilagođavanja. U skladu sa tim, ne postoji univerzalno softversko rešenje koje odgovara svakom preduzeću. Umesto toga, potrebno je opredeliti se za onu opciju koja najviše podržava postojeće ključne procese i koja će ostvariti najbolji odnos između investicija i planiranih rezultata. Trenutne ERP sisteme karakteriše brzina, fleksibilnost $\mathrm{i}$ integrisana cloud platforma. Za operacije koje je pri uvođenju ovih softvera trebalo nekoliko nedelja, danas je dovoljno svega nekoliko minuta. Jedan od razloga nalazi se u njihovoj komplementarnosti sa tehnologijama poput: veštačke inteligencije, mašinskog učenja, interneta stvari i analize obimnih podataka.

Digitalni lanac snabdevanja jednak je potpunoj transparentosti transakcija i protoka robe, usluga i informacija kroz razgranatu mrežu subjekata od dobavljača do kupca. U njemu se prilikom dizajna proizvoda kreira i njegov „digitalni blizanac“ koji predstavlja konkretan proizvod i njegovu poziciju i stanje u realnom vremenu. Planiranje se revidira $\mathrm{u}$ svakom trenutku u skladu sa trenutnim podacima o imovini i poslovanju.

Proizvodnja teži automatizaciji repetitivnih zadataka, prelasku sa determinističkih na predviđajuće modele, sa pisanih na 3D radne instrukcije. Logistika se takođe posmatra sa holističkog aspekta. Teret se konsoliduje, rute optimizuju, a skladišta automatizuju. Upravljanje imovinom sastoji se od preventivnog i uslovnog održavanja, saradnje sa proizvođačima i operaterima na osnovu centralizovane baze podataka i napredne analitike za inženjerske simulacije.

\section{LITERATURA}

[1] Martin Christopher „Logistics \& Supply Chain Management, Fourth Edition “, 2011

[2] Neđo Balaban, Živan Ristić, Jovica Đurković, Jelica Trininić, Pere Tumbas, ,, Informacione tehnologije $i$ informacioni sistemi, sedmo izdanje“" Novi Sad, 2012.

[3] Graham C. Stevens "Integrating the Supply Chain", International Journal of Physical Distribution \& Materials Management, osmo izdanje, Vol. 19, pp.3-8

[4] Kari Korpela, Jukka Hallikas, Tomi Dahlberg, „Digital Supply Chain Transformation toward Blockchain Integration", Proceedings of the 50th Hawaii International Conference on System Sciences, 2017.

[5] https://www3.technologyevaluation.com (pristupljeno u aprilu 2019.)

[6] https://open.sap.com/courses (pristupljeno u maju 2019.)

\section{Kratka biografija:}

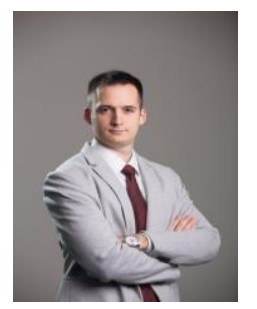

Marko Obradović rođen je u Novom Sadu 1993. godine. Diplomirao je na Ekonomskom fakultetu, a masterirao na Fakultetu tehničkih nauka iz oblasti Inženjerskog menadžmenta 2019. godine. Trenutno je zaposlen u kompaniji Clover. 